\title{
Vidas Presas: uma Tentativa de Compreensão da Tragédia da Criminalidade Junto Às suas Personagens Prisioneiras ${ }^{1}$
}

\author{
Luiz Carlos da Rocha ${ }^{2}$ \\ Universidade Estadual Paulista
}

\begin{abstract}
Este artigo apresenta uma pesquisa sobre os fatores produtores da criminalidade realizada no início da década de 80, que, com o apoio de longas entrevistas com presidiárias, elaborou um conjunto de hipóteses para o entendimento das relações constitutivas que esse fenômeno mantém com a pobreza, com a violência policial/carcerária e com os próprios saberes especializados pelos quais seus atos e atores tornam-se objeto de conhecimento. Sua apresentação, hoje, acalenta dois objetivos. O primeiro é, em homenagem de reconhecimento e gratidão a Sylvia Leser de Mello, oferecer um simples exemplo, dentre tantos, de uma das muitas aventuras de pesquisa propiciadas por sua orientação. O segundo é compartilhar com pesquisadores do tema um estudo que, polêmico e inovador à época, mantém pertinência às características especialmente graves atualmente apresentadas pelas questões abordadas.
\end{abstract}

Descritores: Crime. Violência. Nível socioeconômico.

$\mathrm{Q}$ uero, de início, fazer registro do sentimento de orgulho e admiração que nos causa a recente atitude de Sylvia Leser de Mello que, na contra-mão da avalanche de aposentadorias precoces que esvaziam a universidade pública, acaba de atropelar olimpicamente o retrógrado estatuto da aposentadoria

1 Este artigo resume uma dissertação de mestrado em Psicologia Social defendida na USP, em 1984, sob orientação de Sylvia Leser de Mello, a quem esta rememoração é dedicada.

2 Docente da Universidade Estadual Paulista, Campus de Assis. Endereço eletrônico: lcrocha@assis.unesp.br

Psicologia USP, 2006, 17(3), 49-76. 
compulsória, permanecendo onde sempre fez questão de estar: no exercício do que é mais necessário e desafiador. Sempre atenta à elevada noção de responsabilidade social que orientou sua carreira universitária, vamos encontrá-la, hoje, no exercício da coordenação da Incubadora de Cooperativas Populares da Universidade de São Paulo.

Gostaria, também, como seu ex-aluno de graduação, mestrado e doutorado, deixar algumas palavras sobre aquela que foi sempre minha inspiração como pesquisador, orientador e professor universitário. Mas nada daquelas menções curriculares tiradas do Lattes, mesmo porque para pessoas como Sylvia, a palavra Lattes sempre evocará a lembrança de um físico brilhante, nunca a de um quantificador de carreira que vem se tornando a razão de ser de tanta gente que ocupa a universidade sem, contudo, habitá-la plenamente, como ela sempre fez. Quero deixar apenas o testemunho muito pessoal de algumas passagens, lembranças simples e antigas, cujo significado levo, hoje, menos na memória que na própria forma que vim a ser.

\section{Da professora que não queria saber da ditadura}

Conheci Sylvia Leser no começo dos anos 70, quando iniciava minha graduação em Psicologia na USP. Vivíamos o período mais duro do regime militar que golpeara a democracia brasileira em 64. Cercados por prisões arbitrárias, desaparecimento de colegas e sob forte censura da imprensa, sofríamos a insegurança inerente à suspensão dos direitos de expressão e informação que se estendia ao cotidiano das aulas. Os professores precaviam-se de qualquer conteúdo que pudesse atrair a atenção da ameaçadora presença militar que, no duplo sentido, vigiava estreitamente a universidade.

Pois foi na plenitude desses anos de chumbo que as aulas de Psicologia Social nos surpreenderam com a apresentação de textos sobre materialismo histórico e dialético, economia política, ideologia e outros temas próprios do pensamento marxista.

Lembro-me que os alunos mais politizados, como se dizia na época, perguntavam-se uns aos outros quem era aquela professora que ousava ensinar

aquilo que a força militar proibia tão drasticamente: "Será que ela não sabe 
que estamos em plena ditadura militar?" Essa professora era Sylvia Leser, que sabia muito bem da ditadura, mas sabia também de suas responsabilidades universitárias. Bem por isso, com a coragem que lhe é característica, assumia os riscos de nos trazer um saber que não poderíamos obter em outras aulas, nas bibliotecas e nas livrarias, posto que, na época, era proibido e sumamente arriscado até mesmo guardar em casa um livro marxista. Alguns não viveram esses tempos, mas é preciso que se saiba que era assim.

Os primeiros textos marxistas das aulas de Psicologia Social deram oportunidade à criação de grupos de estudo que, clandestinamente, permutavam, reproduziam e estudavam, com o afinco dos resistentes, aquelas obras que o poder queria excluir de nossa formação. Acho que nunca estudamos tanto e tão bem escondidos. Mas nos sentíamos bem fazendo isso. Fazer do estudo um ato de coragem e resistência nos dava um insubstituível sentimento de dignidade, sem o qual nossa passagem pela universidade teria pouco ou outro significado em nossa formação profissional e em nossa perspectiva de vida. Naqueles anos bons, mas difíceis, aprendemos com Sylvia Leser muito mais que métodos e concepções dos quais o obscurantismo ditatorial nos queria ignorantes. Aprendemos que, mesmo sob riscos graves e justificados motivos para receio, a vida universitária não pode prescindir de coragem.

\section{Da orientadora que não quer seguidores}

No final da década de setenta, já como seu orientando de mestrado em Psicologia Social, procurei Sylvia Leser com uma dúvida. Estava vivamente animado com um conjunto de prisioneiras que conhecera por ocasião de uma peça de teatro apresentada num presídio de São Paulo e achava que poderia advir daí um bom trabalho de pesquisa sobre criminalidade sob a ótica dos prisioneiros. Mas não tinha a mínima idéia de como concretizá-lo, uma vez que não encontrara suporte bibliográfico adequado e o tema encontrava-se completamente fora de minha experiência de trabalho e da especialidade de minha orientadora.

Por outro lado, tinha nas mãos um estudo amostral quase pronto sobre profissionalização de psicólogos que, fruto do meu trabalho como professor de metodologia de pesquisa, prometia uma dissertação de mestrado absolutamente tranquiila, ainda que isenta de qualquer entusiasmo. 
Estava certo de que Sylvia me aconselharia a fazer a dissertação em torno da pesquisa com psicólogos, uma vez que estava bem adiantada e se inspirara justamente em seu excelente trabalho Psicologia e Profissão em São Paulo (Mello, 1975), o que prenunciava uma boa dissertação e, principalmente, uma orientação simples e absolutamente não problemática. Além disso, eu havia aprendido que nada agrada mais a um orientador que uma proposta bem resolvida de continuidade de seu próprio trabalho. Mas esse lugar comum não era o da minha orientadora. Para surpresa de minha pragmática expectativa, Sylvia Leser me incentivou a tomar o caminho daquilo que me entusiasmava, ou seja, o de estudar um tema ligado à criminalidade, para o qual não tinha nenhum preparo prévio, nenhum trabalho realizado, nada, enfim, além da idéia vaga e arriscada de inverter a ótica pela qual o tema costumava ser abordado. Como ela referiu-se ao meu entusiasmo como critério, cheguei a ponderar, ainda que com pouca sinceridade, que também me animava muito dar continuidade à sua pesquisa. Lembro-me até hoje do que me disse na ocasião: "não é importante nem preciso que você se preocupe em dar continuidade à minha pesquisa, mas o importante é que você possa encontrar um tema com o qual se identifique para, então, construir seu próprio trabalho." Ponderou sobre as dificuldades que eu encontraria em estudar esse tema novo e controverso. Mas disse tudo o que um orientando deseja ouvir de seu orientador: que estaria ao meu lado para enfrentar todas as dificuldades que eu encontrasse.

Foi por esta generosidade rara que fui acompanhado no meu próprio caminho de pesquisador no mestrado, com Vidas Presas e no doutorado, com A Prisão dos Pobres. Compreende-se, portanto, por que os trabalhos realizados sob a orientação de Sylvia Leser são tão diversificados, ousados, polêmicos e interessantes, sempre abordando temas relacionados ao drama dos oprimidos e aos problemas populares. É que eles foram acompanhados pela sensibilidade de uma orientação generosa, que não quer fazer seguidores, mas propiciar o encontro do orientando com seu próprio caminho de pesquisador e professor universitário.

São essas as lembranças simples e pessoais, mas fundamentais para este professor universitário, que eu queria evocar sobre Sylvia Leser de Mello. A todos que já a conhecem, não teria sido preciso dizer nada. Mas aos que ainda não tiveram essa sorte, deixo seus descritores mais apropriados: generosidade, coragem, responsabilidade social, sensibilidade, pessoa imprescindível. 
Vidas Presas: Uma Tentativa de Compreensão da Tragédia da Criminalidade...

Passemos, então, a um exemplo das trilhas que um caminhante pode abrir, quando acompanhado pela orientação dessa pessoa imprescindível.

\title{
Vidas Presas: uma tentativa de compreensão da tragédia da criminalidade junto às suas personagens prisioneiras. ${ }^{3}$
}

\begin{abstract}
As trilhas da pesquisa
Tem um pessoal estranho aí fora!'

Não deu tempo pra nada. Me pegaram logo pelo pescoço e jogaram num carro. Ficaram rodando pelas quebradas, me esculachando, e eu já tava toda machucada quando me puseram um capuz e me levaram para um lugar não sei onde. Me jogaram numa cela e disseram que eu tinha até de manhã pra pensar. Eu pensei mesmo. Já sabia que ia ser pendurada e pensei: tudo que eu ouvi falar vai agora acontecer. Mas eu não vou cagüetar ninguém, não vou trazer ninguém pra cá de maneira alguma. Sei que tem gente que não agüenta, compreendo isso. Mas se eu não agüentasse eu não seria digna da vida. E eu não vou andar por aí de cabeça baixa. É um negócio de opinião: meti na cabeça que não cagüetava e pronto! Chegou de manhã me requisitaram. Encapuzada, me levaram por até uma sala onde me tiraram o capuz. Vi o cavalete - dois tocos com um ferro em cima e oito homens com cara de carrascos:

- Fala onde está o cara que nós já vamos daqui.

- Não sei.

- Então tira a roupa.

- Não tiro.
\end{abstract}

Tiraram minha roupa a bofetão, rasgaram tudo e me deram porrada no estômago até eu cair no chão. Amarraram minhas mãos, minhas pernas e me penduraram no cavalete. Prenderam uns fios nos dedos do meu pé, na mão, no bico do meu seio e começaram a rodar a manivela do choque:

3 Buscou-se aqui, tanto quanto possível, manter o formato geral da dissertação original. Mas partes inteiras tiveram que ser excluídas, dentre as quais, infelizmente, as que continham os depoimentos que, com suas 75 páginas, excederia em muito o espaço deste artigo. Ainda que pese esta falta, conforta saber que aqueles depoimentos, na época, circularam muito, de mão em mão, por celas e pátios de prisões que hoje, espera-se, não contenham mais as cooperativas depoentes e os atentos leitores que, então, neles se reconheciam. 


\section{Luiz Carlos da Rocha}

- Fala pra Santa Catarina te ajudar agora!

Sentia todo meu corpo repuxar - horrível! - e como eu gritava muito, encheram minha boca de pedaços de cobertor com urina até sufocar os gritos. Continuaram com os choques e, rindo, me falaram:

- Quando você quiser falar alguma coisa, é só levantar o dedinho. ${ }^{4}$

Pois bem, então eu é que "levanto o dedinho". Também não sei onde está o tal cara, nem sei quem ele é e se soubesse, faria o possível para não dizer. Mas pretendo falar algumas coisas sobre a tragédia da criminalidade e suas personagens, bem como fazer o máximo para acabar com alguns métodos (exemplo logo acima) pelos quais as chamadas "forças da lei e da ordem" constroem seus saberes quanto aos chamados "criminosos".

Mas não é fácil para um psicólogo colher elementos significativos sobre a criminalidade: A Psicologia sabe pouco a esse respeito. Nossa psicometria tem sido utilizada para examinar detentos, mas creio que os psicólogos nunca tenham manifestado propriamente entusiasmo em vê-la utilizada na determinação de "periculosidade" pessoal de pessoas forçadas a viver sob condições perigosas. Tampouco ficam felizes, creio, quando seus conhecimentos sobre controle comportamental são transformados - sob o modelo panóptico - em tecnologia disciplinarista capaz de introjetar nos detentos as grades carcerárias. Nosso desconhecimento quanto aos fatores sociais que envolvem a criminalidade, bem como nosso relativo isolamento das demais ciências humanas, têm cobrado seu preço: passamos décadas estudando limitadamente o "comportamento criminoso" para, como fez Feldman (1979) após analisar 700 títulos, concluir que a aprendizagem é bastante importante, a predisposição pode atuar em casos extremos, a rotulação social tem influências sobre o rotulado, e que recompensas e ônus associados ao comportamento criminoso devem ser considerados: a mesma coisa que Sutherland (1949) já sabia (e editava) 30 anos atrás!

Temos que reconhecer que os problemas da criminalidade são estudados de maneira muito limitada (e inadequada) pela Psicologia. Noções de "comportamento criminoso", agressividade e medidas de traços de personalidade não ajudam muito a quem procura compreender os determinantes da criminalidade.

$4 \quad$ Fragmento de depoimento de uma prisioneira 
Vidas Presas: Uma Tentativa de Compreensão da Tragédia da Criminalidade...

Mas, por meio de conversas, leituras e encontros de estudo, percebi coisas animadoras.

Vários estudos, ainda que vinculados à estrutura acadêmica, não se prendem mais aos limites estritos das cadeias (no duplo sentido) conceituais e metodológicas das disciplinas científicas de onde se originaram. Quando Violante (1984) ajudou a desvendar a linha de montagem (ou desmontagem?) pela qual instituições como a FEBEM reproduzem a criminalização do menor, não houve quem perguntasse por que uma tese de Psicologia Social iniciava suas conclusões falando da acumulação de capital e terminava comentando a ação policial do Estado. Nem surpreendeu ninguém que Ramalho (1979), um sociólogo, apontasse mediações psicológicas em estudo sobre presos baseado no pensamento de um filósofo.

Parece que muita gente acredita que a questão da criminalidade, entre outras, não pode ser bem compreendida sob os restritivos limites de uma ou outra das numerosas ciências em que o conhecimento do Homem e de suas relações foi arbitrariamente retalhado. Talvez arejados pelo relativo enfraquecimento do autoritarismo institucional, estamos todos reaprendendo que a divisão e isolamento das ciências humanas nunca teve por objetivo descobrir, mas ocultar as questões incômodas em vias de serem conhecidas.

Creio que a tendência reunificadora das ciências humanas, longe de simplesmente misturar diferentes sistemas e métodos, abre de fato um espaço mais amplo para o entendimento da criminalidade. É um convite às ciências jurídicas, sociais, econômicas, psicológicas, semióticas e culturais a abandonarem os solilóquios pelas quais reiteram seus saberes e reunirem-se no estudo conjunto de individualidades que de fato tenham sentido e existência, mesmo porque só assim podem manter suas características de humanidade.

Foi na tentativa de somar esforços com os que pensam assim, que abandonei a idéia de me perguntar o quê a Psicologia poderia dizer sobre a criminalidade e resolvi procurar as questões que me parecessem, como cidadão, pesquisador e psicólogo, relevantes para o entendimento do drama da criminalidade.

Resolvido o problema da identidade do pesquisador, decidi abrir duas frentes de trabalho e estudo. Por um lado, estabeleci contatos com pessoas da 
população criminalizada em presídio da cidade de São Paulo. Por outro lado, desenvolvi o estudo bibliográfico do tema sem restrição de área de conhecimento, mas com atenção especial à Criminologia.

Quanto às visitas ao presídio, estabeleci uma rotina diária onde as tardes foram dedicadas a conversas e entrevistas junto a prisioneiras, às quais a sorte impôs ampla experiência com a chamada vida do crime ${ }^{5}$. Essas pessoas, contudo, em nenhum momento foram tratadas como objeto de estudo, mas como sujeitos de um conhecimento particularmente claro sobre a criminalidade e, talvez por isso, oficialmente negado. Ora em grupo, ora em par, passeamos pelos pátios, trocamos nossas verdades, impressões e experiências de vida, sempre longe dos ouvidos institucionais. Não demorou muito para que nossa camaradagem preocupasse alguns funcionários e acabasse por interromper a possibilidade daquele convívio. Mas já era tarde: tínhamos já nos compreendido perfeitamente e a interrupção não fez mais que corroborar nossa visão comum.

Do ponto de vista técnico, é possível dizer que a metodologia utilizada foi uma combinação da entrevista aberta de Bleger (1980), que permite ao entrevistado configurar o campo da entrevista, com as técnicas dialogais da pesquisa participante definidas por Borda e Brandão. Conforme Borda (1983),

o pesquisador deve abandonar a arrogância do erudito, aprender a ouvir discursos concebidos em diferentes sintaxes culturais, adotar a humildade dos que realmente querem aprender e descobrir: romper com a assimetria das relações sociais entre entrevistado e entrevistador e incorporar pessoas das bases sociais como indivíduos ativos e pensantes no esforço da pesquisa. (p. 55)

Brandão (1984), por sua vez, ensina que

a maneira espontânea de um entrevistador falar sobre qualquer assunto é através de sua pessoa, sua história de vida ou através de um fragmento de relações entre sua vida e aquilo que responde. Em boa medida (o pesquisador) descobre que métodos e técnicas de que se arma com cuidado são meios arbitrários pelos quais o investigador submete à sua a vontade do outro, o investigado. (p. 13)

5 As pessoas ditas "do crime" têm, geralmente, uma história de consistente envolvimento com atividades de assaltos à mão armada. São consideradas altamente perigosas pelas instituições policiais e carcerárias, mas gozam de inequívoca liderança e respeitabilidade junto à população criminalizada, cujo "proceder" (conjunto de princípios éticos) cumprem e fazem cumprir. 
Vidas Presas: Uma Tentativa de Compreensão da Tragédia da Criminalidade...

Sob a inspiração desses cuidados, foram desenvolvidas as entrevistas que resultaram em depoimentos que oferecem apoio às hipóteses desse trabalho. Mas, a bem da verdade, impõe-se registrar, aqui, que tudo foi resultado de uma interação franca, honesta e cooperativa, cujo clima só não foi plenamente prazeroso pela presença institucional que mantinha viva em todos nós a advertência inicial deste trabalho:

“Tem um pessoal estranho aí fora!”

\section{Hipóteses formuladas pela pesquisa}

Sumaria-se, a seguir, na forma de um conjunto de hipóteses, o Modelo de Processos de Criminalização da População Pobre obtido como resultado desse trabalho de pesquisa, apresentado como uma alternativa de entendimento da dinâmica produtora e reprodutora da tragédia criminal, conforme experienciada hoje pela sociedade brasileira.

Hipótese Um: o desenvolvimento da criminalidade tem como determinante básico um processo político-econômico que impele ao crime a população pauperizada e sem alternativa legal de prover sua subsistência.

A expansão do modelo capitalista de desenvolvimento expulsa enormes massas de trabalhadores do campo, cria profunda desproporção entre oferta e procura de empregos nas cidades, rebaixa salários, elimina postos e alternativas de trabalho regular. Em consequiência, forma-se nas cidades uma crescente população pauperizada e sem possibilidade de prover seu sustento por meio do trabalho, cuja miséria e desesperança contrastam violentamente com a riqueza acumulada, da qual não podem participar. Sob tais contingências, é trágico, mas perfeitamente compreensível, que muitas pessoas acabem por encontrar no trabalho-crime, e não no legal, o meio possível de dar sustento e sentido às próprias vidas.

Hipótese Dois: o desenvolvimento da criminalidade é administrado por um processo institucional carcerário-policial de criminalização da população pobre.

A criminalização da população pauperizada não é só o resultado de mera pressão econômica. A própria trajetória de sua difícil e incerta inserção 
no mundo do trabalho é permanentemente vigiada e "disciplinada" por ação de caráter policial. Mas onde a ordem social depende diretamente da violência da força policial, esta faz mais que vigiar "desvios": ataca todo sinal de suspeição, e a miséria e a desocupação são os mais visíveis deles. Presos para averiguações, fichados, espancados, humilhados e sob permanente suspeita institucional, os trabalhadores pauperizados e sem trabalho recebem, a priori, todo peso legal e extralegal das medidas policiais contra o crime. Criminalizados antes do delito e pagando prévia e permanentemente pelo crime que ainda não ousaram, muitos deles acabarão por se dobrar à lógica da violência policial e da criminalidade: por meio do crime terão ao menos uma compensação, uma vez que já aprenderam a ver a possibilidade de prisão como muito mais ligada aos azares que aos próprios atos. Mas daí o azar é certo e a penitenciária só por acaso não os integrará no crime. Reverter o processo, então, torna-se difícil. Muitos não resistirão à pressão dos setores corruptos das forças policiais e delas se tornarão clientes compulsórios: os roubos e assaltos subseqüentes serão, doravante, o aluguel da liberdade e da vida que não mais lhes pertencem. Enriquecerão respeitáveis receptadores, suplementarão alguns salários das forças da lei e serão apontados ao público como argumento eloqüente da necessidade da violência policial, daquela mesma que os incita e administra.

Hipótese Três: a criminalidade é constituída como objeto de saber por um processo de criminalização da população pobre no âmbito do saber criminológico oficial, que informa "cientificamente" o processo de criminalização institucional.

A criminologia, por meio de estudos históricos, doutrinários e empíricos, acumulou também, além de preconceitos, um bom conhecimento sobre uma série de fatores sociais produtores de criminalidade. Um conhecimento perfeitamente capaz de informar políticas sociais de prevenção da criminalidade. Mas a prática que o conhecimento criminológico possibilita sempre foi mediada por uma política criminal de controle da população pobre. Como os fatores sociais indutores de crime estão intimamente ligados ao próprio caráter das políticas de controle da população pobre, ocorre então uma inversão: as políticas criminais adotam os piores preconceitos da criminologia e transformam os fatores indutores de crime em estigmatizantes criminais. Exemplo disso é a conhecida correlação entre miséria e criminalidade, transformada 
Vidas Presas: Uma Tentativa de Compreensão da Tragédia da Criminalidade...

em estigma criminal da miséria. Assim, abortando o que se poderia prevenir, as políticas criminais centradas na ação policial transformam o conhecimento criminológico (falso ou não) em tecnologia criminalizante "cientificamente" informada e incentivam, pelo uso institucional, a produção "científica" de saberes criminalizantes avalizadores de suas próprias práticas.

Hipótese Quatro: a ocultação dos reais determinantes da criminalidade produz um processo de criminalização da população pobre no próprio imaginário público e as características ligadas a estes determinantes negados tendem a ser projetados na figura do chamado "criminoso".

O aparente enfrentamento institucional, policial e propagandístico da criminalidade oculta os processos de criminalização que a produzem e oferece os elementos da ilusão_ideológica pela qual a criminalidade é publicamente percebida:

1) Abstração ideológica: na aparência tudo se passa como se a criminalidade se desenvolvesse por si própria, a despeito de combatida por todos os recursos do Estado e grupos particulares.

2) Inversão ideológica: todas as características da porção mais pobre da população passam a ser percebidas publicamente como sinais seguros da própria criminalidade: vestimenta simples e surrada, sinais de desnutrição, desemprego, grupo familiar destruído, morar em favela e cortiço, cor de pele, hábitos de linguagem etc.

Assim, a ocultação dos processos de criminalização do trabalhador pauperizado acaba por submetê-lo a um novo e muito mais grave processo de criminalização, agora já ao nível do imaginário público.

Também sob mediações ideológicas, características ligadas aos processos de criminalização são percebidas como se fossem da própria personalidade ou natureza da pessoa criminalizada: "o criminoso não se prende a nada", "é ocioso e vagabundo", "é violento e descontrolado", "imoral e psicopata", e, por fim, "desumano". 


\section{Um breve histórico crítico do conhecimento criminológico}

Durante a Idade Média, os poderosos não precisavam de conhecimentos criminológicos para justificar suas execuções: reivindicavam para as próprias ações o aval divino, portanto podiam muito bem debitar as de suas vítimas na conta dos demônios. E sintomaticamente, o ato de pronúncia inglês acusava o réu de ser "inspirado e instigado pelo diabo e de não temer a Deus diante de seus olhos" (Sutherland, 1949, p. 63). A confissão sob tortura referendava a justiça do julgamento e a execução brutal e pública exercia, pelo exemplo, a profilaxia da contestação do poder e de suas normas.

Mas a mobilidade econômica propiciaria a ascensão de uma nova classe social cujos critérios de controle social e de legitimação do próprio poder eram os da atividade que a fazia poderosa: o comércio, os negócios, a exploração do trabalho alheio.

\section{A Escola Clássica}

Na segunda metade do Século XVIII, aparece, sob a influência da reforma legalista européia, a primeira escola de criminologia, mais tarde chamada Escola Clássica. A Penalogia e a Legislação assumem papel importante, e passam a ser pensadas a partir de uma economia psicológica de sofrimentos e prazeres, onde se supõe que a ameaça de sofrimento da pena possa contrabalançar, na devida proporção, a esperança de ganho do delito. O réu, já isento da suspeita de instigação demoníaca, passa a ser concebido como alguém que pesou bem as possibilidades de perdas e ganhos e, por fim, escolheu livremente a própria sorte: uma lógica de negociantes.

Mas reconhecer os fundamentos ideológicos da Escola Clássica não significa negar seu caráter inovador e, então, revolucionário. Foram nomes ligados a esta escola que iniciaram a modificação sistemática dos velhos métodos punitivos feudais, inaugurando uma nova forma de disciplina: Jeremy Bentlham se opôs frontalmente à brutalidade das penas e às torturas nas prisões, ainda que tenha proposto o sistema Panóptico, onde a pena deve ser cumprida sob permanente vigilância e disciplina. 
Vidas Presas: Uma Tentativa de Compreensão da Tragédia da Criminalidade...

Mas o nome mais expressivo ligado a Escola Clássica é o de Cesare Bonesana, Marquês de Beccaria, que, tendo vivido o ambiente intelectual libertário que constituiria o ideário da Revolução Francesa, pregou princípios e normas que, a despeito de comporem o próprio cerne da Escola Clássica, demandariam e demandarão ainda muito tempo para serem cumpridas: as penas devem ser moderadas, iguais para todos, proporcionais ao delito e definidas por lei. O réu não deve ser considerado culpado antes do delito. A prisão preventiva não é sanção, mas meio de assegurar a pessoa do acusado e deve ser tão suave quanto possível. Somente os magistrados devem julgar os acusados e não devem interpretar a lei. As acusações não devem ser secretas. $\mathrm{O}$ objetivo da pena não é atormentar o acusado, mas impedir que pratique novo delito e dissuadir os demais de delinqüir. A atrocidade das penas opõe-se ao bem público. A sociedade não tem o direito de aplicar a pena de morte. A tortura ao acusado é uma barbaridade. Mais útil é a prevenção do delito que sua repressão penal. As penas não são justas se a sociedade não empregou os meios para prevenir os delitos. O roubo é ocasionado geralmente pela miséria e desespero.

Perfeitamente consciente das forças e interesses que desafiava, Beccaria editou, em 1764, sua Dissertação sobre os Delitos e as Penas na clandestinidade onde, conforme Senderey (1978), alertava explicitamente: "Eu quis defender a Humanidade sem ser um mártir dela" (p. 19).

Hoje, é bem conhecido o destino de seus princípios: foram escolhidos a dedo, incorporados os inofensivos, esquecidos os perigosos. Mesmo assim, a Escola clássica é considerada (que ironia!) a própria base do direito penal moderno.

A concepção de igualdade entre os homens que animava Beccaria era uma esperança, não uma constatação. E a esterilização do conjunto de seus princípios se deu sob as mesmas forças das quais temia tornar-se mártir.

Mas os poderes que ameaçavam as esperanças de Beccaria fariam novas descobertas: a ciência positiva, já razoavelmente experiente na dominação da natureza, ensaiava o domínio do ser humano com Augusto Comte. E a reflexão sobre as relações entre os homens, de uma atividade de esperanças claras construídas sob constatações implícitas, seria transformada em seu contrário: uma "ciência" de constatações explícitas, organizadas sob esperanças ocultas. 


\section{A Escola Geográfica}

Sob inspiração da objetividade, desenvolveu-se a primeira escola dita científica dedicada ao estudo da criminalidade. Geográfica ou Cartográfica, seu nome deriva-se de extensos estudos estatísticos da distribuição dos crimes em relação a áreas e condições geográficas e sociais. Os estudos correlacionais acabaram por estabelecer forte vínculo entre as condições econômicas e a criminalidade. Conforme Senderey (1978), Ducpétiot, em 1850, percebeu que as crises econômicas produziam extraordinário aumento da criminalidade. Cristophe encontrou o mesmo aumento associado à mecanização industrial, e conseqüente desemprego, na Inglaterra do século passado. Na mesma linha, Von Mayr chegou a constatar que, em média, a cada centavo de aumento no preço do trigo, havia mais um roubo para cada cem mil habitantes. Quetelet, o mais expressivo nome dessa escola, considerava o delito como fenômeno claramente social e estudava sua relação com a miséria, o analfabetismo, as faixas etárias, sexo e até mesmo variações climáticas modificadoras das necessidades humanas.

Segundo Sutherland, a escola geográfica, de 1830 a 1880, desenvolveu estudos de distribuição da taxa de crimes, delinqüência juvenil e crime profissional, muito superiores a tudo o que se faria nos 50 anos subseqüentes.

Mas estabelecer relações e mapear a produção social do crime não significa, necessariamente, acumular condições suficientes para o enfrentamento de suas causas. A capacidade heurística da ciência entusiasmava o poder econômico quando lhe ampliava as possibilidades de exercício. Porém o entusiasmo revertia-se em hostilidade quando a pesquisa ameaçava descobri-lo como o próprio produtor da criminalidade. Então não era mais ciência, pois extravasava os objetivos políticos pelos quais era mantida.

O esforço de objetividade imparcial da primeira escola científica de criminologia se diluía pela ausência de um projeto de enfrentamento dos fatores causais que descobriu. Quetelet, cuja obra Física Social, editada em 1835, já pelo sugestivo título denotava a grandeza das esperanças positivistas, seria preterido por sua própria cientificidade. Pois "ciências" mais simpáticas às práticas arbitrárias do poder estavam já em premeditação. 
Vidas Presas: Uma Tentativa de Compreensão da Tragédia da Criminalidade...

\section{A Criminologia Positiva}

"Fui apresentado em Turim a um jovem sábio desconhecido, chamado Cesare Lombroso, que disse pretender ter descoberto o delinqüente nato nos caracteres e nos traços fisionômicos. Que felicidade para os juízes de instrução!"

Segundo Senderey (1978), esta seria a primeira menção pública sobre Lombroso, feita pelo jornalista belga de nome Emile Laveieye, na década de 60 do século XIX.

Lombroso provocaria um entusiasmo jamais igualado entre os responsáveis pelo funcionamento do aparelho jurídico e policial de quase todo o mundo, justamente por oferecer elementos de credibilidade científica a antigos preconceitos quanto à relação entre o crime, fatores raciais e características associadas à miséria.

Mesmo antes, em plena Idade Média, a Oftalmoscopia, a Metoscopia, a Quiromancia e principalmente a Fisiognomia de Della Porta acalentavam a esperança de ler o caráter dos indivíduos por meio do exame dos olhos, rugas, mãos e fisionomia facial. E já entusiasmavam juízes. Conforme Senderey (1978), o Marquês de Moscardi, em Nápoles, costumava iniciar suas sentenças com "ouvidas acusação e defesa e examinadas tua face e cabeça", seguidas de invariáveis condenações à morte ou prisão perpétua.

Note-se, portanto, que não faltavam crendices preconceituosas para inspirar Lombroso, sendo que seu trabalho de médico militar e, posteriormente, médico de manicômio judiciário em Pesaro, na certa ofereceu campo propício a tal contato.

Sua obra mais conhecida é L'uomo Delinquente, publicada em 1875, onde Lombroso desenvolve sua teoria caracteriológica. Crânio assimétrico, pragmatismo, nariz achatado, orelhas grandes e barba escassa, eram os elementos básicos para o reconhecimento do criminoso nato. Taras degenerativas fisiológicas e psicológicas completavam o quadro que permitiria aos juízes a condenação, com suposto embasamento científico, de pessoas cujas características raciais e sinais de miséria faziam-nas objeto de perseguição dos poderosos.

Lombroso acompanhou e fortaleceu os piores preconceitos antropológicos de sua época, em sua tentativa de vincular, pelo atavismo, seu genus 


\section{Luiz Carlos da Rocha}

homo delinquens ao ser humano de culturas ditas primitivas. Viu em diferentes hábitos culturais uma tendência assassina e em diferentes morais sexuais supôs a prostituição. Fundou, sob esse espírito, a chamada Antropologia Criminal. Propôs a esterilização de delinqüentes, prenunciando a eugenia nazi-fascista. Criou o conceito de periculosidade pré-delitual, base para a segregação de pessoas independente de delito, ainda hoje em uso.

Em síntese, ao enfatizar a gênese biológica, psicológica e cultural da criminalidade, Lombroso e sua Escola Positiva foram os sistematizadores dos piores vícios e preconceitos pelos quais uma sociedade violenta e injusta tentava safar-se de suas responsabilidades e transferi-las às suas próprias vitimas. Ao mesmo tempo, foi um exemplo dos mais gritantes da tentativa de compor uma terminologia de aparência científica para legitimar práticas, objetivos e esperanças inconfessáveis.

As bases de suas teorias foram absolutamente contestadas por estudos empíricos já no começo de nosso século. Em 1910, Goring, após rigorosas observações comparativas, diria que era mais fácil distinguir um estudante escocês de um inglês que um catedrático de um delinqüiente. A ênfase endógena de Lombroso e seus preconceitos quanto às minorias raciais, índios, pobres, crianças e excepcionais foi contestada e denunciada por cientistas e pesquisadores de todas as áreas científicas pertinentes. Mas a despeito de ser apresentado há décadas como exemplo trágico de desacerto científico, o pensamento de Lombroso ainda hoje é amplamente acolhido por profissionais e autoridades das áreas judicial, policial, psiquiátrica e carcerária, principalmente por meio da incorporação parcial que dele fizeram seus colaboradores Garófalo e Ferri. Despreparo científico, ignorância ou sabedoria perversa, a permanência do pensamento lombrosiano e assemelhados pode ser entendido como, usando seus termos, uma perigosa predisposição mistificadora presente nas áreas institucionais que administram a criminalidade. Bem a propósito, um ex-secretário de Segurança Pública de São Paulo, Erasmo Dias, declarava: "O bandido tupiniquim, o nosso bandido, tem tipologia definida: está sempre abaixo da média, é subnutrido, mal vestido, subempregado, enfim, tem psicossomática bem definida" (Benevides, 1983, p. 53). 
Vidas Presas: Uma Tentativa de Compreensão da Tragédia da Criminalidade...

\section{A Escola Sociológica}

A contestação da caracteriologia criminal, do privilegiamento endógeno e da conseqüente política criminal eugenista de base lombrosiana foi promovida, principalmente, pela chamada Escola Sociológica (ou Francesa) de Gabriel Tarde (1834-1904). Em sua obra As Leis da Imitação, editada em 1890, Tarde caracteriza a criminalidade como um fenômeno fundamentalmente social e explica a reprodução dos padrões delinqüentes com base na imitação. A retomada da ênfase social nos determinantes da criminalidade, além de conter a fúria discriminatória dos endogenistas, possibilita a abertura de novas e interessantes perspectivas de estudo. Sutherland, criminólogo americano, deu instigante desenvolvimento às concepções que privilegiam a aprendizagem social como fator causal de reprodução da criminalidade. Resumindo sua teoria do comportamento criminoso, pode-se dizer que este se desenvolve em associação com padrões criminosos, exatamente da mesma forma que se reproduz o comportamento legal. Qualquer característica pessoal só teria relevância quando afetasse a freqüência ou consistência da associação diferencial do indivíduo em relação aos padrões criminosos ou legais. Sutherland remete a associação diferencial aos conflitos culturais e estes a desorganização social, compondo, respectivamente, a causa específica, fundamental e básica do comportamento criminoso.

Sua teoria da associação diferencial pode, em princípio, ser percebida como um modelo que enfatiza a aprendizagem social do crime e a relaciona a fatores socio-organizativos conflitantes. Mas Sutherland era desses pensadores capazes de superar as limitações ideológicas que eludem os fatos. Percebeu claramente que a cultura criminosa não se restringia meramente aos aspectos discriminados pela legislação:

As mais intrincadas maquinações dos homens das profissões liberais e de negócios podem ater-se à lei tal como é interpretada, mas serem idênticas na lógica e nos efeitos ao comportamento criminoso que resulta em prisão. Essas práticas, ainda que não resultem em condenação como crime, fazem parte da cultura criminosa. (Sutherland, 1949, p. 16)

Compreendendo que "a cultura criminosa prevalece muito mais do que se acredita usualmente", esse autor percebeu o Direito Criminal como 


\section{Luiz Carlos da Rocha}

originado do conflito entre grupos sociais e constituído em conveniente divisor de águas das práticas sociais das classes que se antagonizam.

Quando um grupo de interesses consegue a expedição de uma lei, ele obtém a assistência do Estado num conflito com um grupo rival de interesses: a oposição do grupo rival torna-se assim "criminosa". Os atos danosos existem em todas as classes de nossos dias. As classes superiores têm sutilezas na prática de atos danosos e as classes pobres agem mais diretamente. As classes superiores são politicamente importantes e proíbem os atos danosos das classes pobres, mas as leis se definem e executam de tal maneira que os atos danosos e sutis das classes superiores não caem dentro de seu âmbito. (Sutherland, 1949, p. 25)

Assim, esse autor começou a perceber no Estado e no Direito não mais o poder imparcial que arbitra os conflitos com base no interesse comum, mas um instrumento poderoso que, sob aparência isenta, respalda oficialmente a dominação de uma classe por outra. Por outras vias e métodos, a pesquisa criminológica reencontrou as concepções da Economia Política Crítica que um século antes já compreendia a superestrutura política e jurídica como expressão da dominação econômica. O conservadorismo americano do pós-guerra pode ser obscurantista, mas não é tolo. Conforme Taylor, Walton e Young (1980), Tappan percebeu bem as conseqüências indesejáveis de uma ciência criminológica que não cumpra seu papel na legitimação do poder econômico:

Os rebeldes podem gozar uma verdadeira orgia condenando como criminoso a quem queiram... e relegando às classes criminosas todo capitalista exitoso. Isto é pura vociferação marginal contra o sistema vigente! Isto não é criminologia. Isto não é ciência social! (p. 48)

A verdade é que não pode ser aceita como científica uma criminologia que não aceite o pacto implícito de respaldar a ação do poder econômico e criminalizar os dominados desviantes. Ainda assim, Sutherland, que substituíra as definições legais de delito pela de dano social, demonstraria amplamente que os crimes de colarinho branco e de capital produziam mais vítimas e prejuízos que os crimes previstos e perseguidos pela lei. 
Vidas Presas: Uma Tentativa de Compreensão da Tragédia da Criminalidade...

\section{A Criminologia da Revelação}

Sob essas bases constituiu-se a Criminologia da Revelação (ou Expo$s e ́)$, que pleitearia a responsabilização criminal de elementos das elites econômicas por delitos cujo montante tornaria o mais bem sucedido assaltante mero principiante varejista. Apenas como exemplo, Frank Pearce calculou o lucro ilegal produzido pelas corporações americanas em 1957 em 9 bilhões de dólares; no mesmo ano, calculou-se em 284 milhões de dólares o montante de prejuízos advindos de roubos e assaltos: a relação é simplesmente de trinta para um. Mas os programas de investigação científica do crime desagradaram profundamente o pensamento conservador que, por conveniência, abandonou seu credo positivista e exigiu critérios morais e legais para a ciência criminológica. Já em 1958, conforme Taylor et al. (1980), George Vold assinalava:

Existe uma óbvia incongruência na afirmação de que os dirigentes e os elementos mais responsáveis de uma comunidade são também seus criminosos. Os dirigentes de negócios e os executivos das empresas desempenham importante papel cívico e são fonte importante de direção imaginativa nas empresas. (p. 47)

Compreende-se então uma importante diferenciação conceitual: o crime, dependendo da situação socioeconômica de quem o cometa, deve ser considerado "direção imaginativa" e seu autor saudado como um dos "mais responsáveis cidadãos da comunidade". A tendência em verdadeiramente glorificar o crime dos poderosos não admite a possibilidade sequer de sua definição criminal. O próprio Tappan exigiria que a criminologia estudasse não mais que os infratores julgados e condenados, visto que só estes poderiam ser definidos como criminosos. Teríamos, então, que o objeto de estudo da ciência criminológica seria definido não por cientistas, mas por práticas e conveniências de uma Política de Estado. Esse absurdo metodológico não impressionou os juristas e cientistas cujo status elevado correspondia à subserviência ao poder.

E a Criminologia dominante insistiria na propriedade das definições legais e continuaria premeditando respaldo científico ad hoc para sua missão de transferir o ônus de uma organização criminal e criminógena às classes pobres e exploradas. Com Galileu, soubemos que a Santa Sé queria uma Astronomia, mas não aquela que lhe refutasse os dogmas legitimadores de seu poder. Com a pesquisa criminológica aprenderíamos, 400 anos depois, que 
o Estado queria uma Criminologia, mas não aquela que o descobrisse como protetor dos grandes criminosos e gerador de criminalidade em geral.

\section{O Modelo Eclético bio-psico-social}

A relação bastante particular entre a Política Criminal e as ciências que estudam a criminalidade já podia ser observada no "acordo de cavalheiros" que, reunindo a Escola Sociológica de Tarde e a Positiva de Lombroso, inaugurou, no inicio do século XX, a fase eclética da Criminologia. Na época, as relações entre condições socioeconômicas e a criminologia já eram amplamente conhecidas e a Antropologia Criminal de Lombroso já estava em crise terminal. Mas tudo indica que as forças que, na época, deram forma ao ecletismo criminológico (até hoje vigente) mediram-se não por argumentos científicos, mas pelo poder de representação dos interesses sociais, econômicos e políticos em jogo. E não é preciso muita sagacidade para supor quais interesses estavam super-representados: uma rápida análise dos quatro pontos básicos do ecletismo criminológico será suficiente para perceber os critérios de feitura desse verdadeiro "picadinho" de escolas criminológicas diversas.

Em primeiro lugar, estabelece-se a independência do Direito Penal e Criminal com relação à Criminologia ou qualquer outra ciência que estude a criminalidade. De início, parece ser uma herança da Escola Clássica, que introduziu o princípio segundo o qual só as leis poderiam fixar as penas e caracterizar o ato criminoso. No entanto, quando Beccaria lutava por esta justiça, supunha estar combatendo os arbitrários interesses dos poderosos em eliminar, pela criminalização, seus opositores de classe. Hoje, a independência legal tem a função inversa, de criminalizar segmentos que a ciência já demonstrou serem vítimas, e de isentar de responsabilidade criminal agentes do poder econômico cuja ação já foi demonstrada como causadora de profundo dano social. Por outro lado, a independência das leis em relação à ciência revela a incapacidade do poder político-judicial em traduzir o controle e administração da criminalidade na forma de saber técnico-científico aceitável, como já havia feito com a loucura (Castel, 1978; Foucault, 1972). Lombroso foi uma esperança que entusiasmou as instituições jurídicas e policiais, servia como uma luva aos poderosos, mas desgraçadamente para eles, teve resistência científica. 
Vidas Presas: Uma Tentativa de Compreensão da Tragédia da Criminalidade...

Já as formulações científicas que o sucederam estavam marcadas pelo impertinente desrespeito ao livre exercício do capital e pela insistência em explicar a criminalidade associada às condições miseráveis dos explorados. Nunca foram, portanto, dignas da confiança dos que controlam o Estado e precisam de "boas" ciências para suas políticas criminais.

Em segundo lugar, conserva-se a noção de "livre arbítrio" como base da imputabilidade penal. Formulação também da Escola clássica, significa que só pode ser condenada a pessoa que exerceu livre e responsável escolha ao cometer o delito. Como pressão social e econômica não são consideradas co-autoras da escolha, será inimputável apenas o acusado que demonstre não estar senhor de sua razão por motivos compreendidos como endógenos e pessoais. Nesse caso, o acusado será isentado de pena, mas responsabilizado pessoalmente pelos mesmos fatores que lhe suspenderam a responsabilidade. Se for pobre, amargará, talvez para sempre, a condição de cliente tutelado pelas instituições psiquiátricas.

O terceiro ponto do acordo eclético aceita o crime como sujeito a favores causais tanto endógenos como exógenos. O delito, que já fora definido por ação jurídica, sofre agora definição de fenômeno natural e social. Nada poderia ser menos claro, no entanto é a própria confusão do modelo eclético que permite o enquadramento bio-psico-social da ação criminosa, submetendo-a à mesma apreciação causal de qualquer ação humana eventual. Tal equacionamento teórico substitui estudo dos determinantes da criminalidade social pela pesquisa de fatores predisponentes do comportamento anti-social. O resultado é que a criminalidade é negada como manifestação sintomática de desagregação de uma sociedade cujo funcionamento exige e gera permanente violência social e, no lugar do que é negado, inventam-se indivíduos (os criminosos) "pouco resistentes" ou "propensos" à ação criminosa. Os estudiosos podem perceber o embuste, mas é justamente nesses casos que o aparentemente desconjuntado modelo eclético revela-se uma obra prima do oportunismo que caracteriza a relação entre os poderes criminalizantes e as ciências: por um lado, o julgamento científico não conformista é afastado, pela autonomia jurídica, da determinação do que é crime e de quem é criminoso; por outro lado, a plasticidade endo/exogenista e a amplitude do modelo criminológico bio-psico-social permitem a compatibilização e a assimilação de todo tipo de técnicas científi- 
cas na forma de trabalho especializado para apoiar a administração estatal da criminalidade. Assim, o ecletismo criminológico municia-se de ciência sem jamais submeter a questão da criminalidade ao juízo científico.

Por fim, o quarto ponto do ecletismo foi aceitar a noção de estado perigoso, que implica no reconhecimento de que circunstâncias alheias à vontade do indivíduo podem envolvê-lo em atividade legalmente definida como criminosa. Trata-se do reconhecimento de determinações econômicas, sociais, culturais, psicológicas e mesmo biológicas sob as quais o acusado foi impelido a agir. No entanto, como se supõe não estar no alcance da Justiça e da instituição policial-carcerária a modificação de tais condições, o estado perigoso das condições alheias à vontade do acusado será transformado em sua própria periculosidade. A escandalosa inversão de relação causal será operada por exames de periculosidade que transferirão para a responsabilidade pessoal do acusado as condições adversas das quais foi vítima.

Desta forma, a Política Criminal, que fora definida por Feuerbach como o saber legislativo do Estado em matéria de criminalidade, revela-se, sintomaticamente, como o aproveitamento por parte do Estado das normas, princípios e conhecimentos científicos que lhe servem para o controle da criminalidade, na definição reveladora de Senderey (1978).

\section{O impasse}

O fato de a pesquisa científica da criminalidade descobrir relações antipáticas e ameaçadoras aos interesses dominantes não tem implicado na recusa sistemática, por parte do Estado, dessas descobertas. Pior que isso, as políticas criminais de países como o nosso têm revelado uma competente aptidão em subverter as conclusões científicas, transformando-as em municiamento de ação dos poderes, grupos e interesses originalmente denunciados. Podem ser arrolados inúmeros exemplos em que conclusões de pesquisas sobre a criminalidade foram transformadas exatamente no seu contrário:

A conhecida correlação entre miséria e a criminalidade não foi traduzida em política social de eliminação da miséria: fortaleceu a estigmatização criminal dos pobres. 
Vidas Presas: Uma Tentativa de Compreensão da Tragédia da Criminalidade...

A conexão entre criminalidade e apropriação privada do produto social não inspirou forma de socialização do produto: acentuou a vigilância, repressão violenta e criminalização dos expropriados.

A consensual relação entre desemprego e criminalidade não implicou em política de pleno emprego: transformou o desempregado em cliente preferencial da violência policial a ponto da carteira de trabalho assinada ser um verdadeiro salvo conduto, necessário para o trabalhador evitar a prisão.

A relação entre preconceito racial e criminalidade não encaminhou a eliminação do racismo institucional: manteve a suspeita de que o cidadão discriminado racialmente é culpado até prova em contrário.

A clássica relação entre êxodo rural e criminalidade não implicou política de fixação do homem ao campo ou de apoio social ao migrante: transformou-o em suspeito permanente das ações policiais.

A relação entre concentração de riqueza e criminalidade não inspirou política de distribuição de renda: orientou a transformação da polícia pública em protetora particular da grande propriedade, transferindo a criminalidade inter-classes para intra-classes pobres.

As várias idéias de marginalização e suas relações com a criminalidade jamais promoveram política de integração social: estigmatizaram o "marginalizado" até fazer de "marginal" um sinônimo de "delinqüente".

Até mesmo relações entre criminalidade e as vagas idéias de desfavorecimento social, englobando educação, estrutura familiar, socialização e estrutura psicológica, foram transformadas em índices de periculosidade pessoal do "desfavorecido".

A secular e amplamente comprovada ineficiência da prisão na redução da criminalidade, e mais, sua indiscutível ação fortalecedora desta última, nunca arranhou os muros das cadeias: mas ajudaram a fazer de seu egresso alvo preferencial da corrupção policial e da suspeita institucional e pública.

Em síntese, assiste-se a um drama onde a Política Criminal, na prática, prostitui o equacionamento científico da criminalidade, apropriando-se de suas descobertas, subvertendo-lhes o sentido e transformando-as, de elementos de conhecimento dos determinantes da criminalidade, em fatores de informação 
"científica" de um verdadeiro processo de criminalização institucional, cujas vítimas são, desgraçadamente, a própria população pobre que o pesquisador tinha a intenção de defender.

\section{Alternativas}

O cômodo e anedótico mito da incompetência das instituições estatais no controle da criminalidade tornou-se absolutamente não convincente. Entende-se cada vez mais a profunda competência dos agentes institucionais da Política Criminal em fazer da criminalidade o bode expiatório dos efeitos socialmente trágicos de políticas sociais e econômicas absolutamente antipopulares. Percebe-se que tais políticas só podem ser mantidas sob rígido controle policial-militar de suas milhões de vítimas e a própria criminalização de parte delas é transformada em argumento legitimador do rígido controle policial sobre a população pobre. Fortalece-se a suposição de que os fatores geradores da criminalidade e da criminalização sejam os mesmos que sustentam e reproduzem as condições de poder das classes sociais cujos interesses estão fortemente representados nos aparelhos de Estado. Como consequiência desse entendimento, a politização e entrelaçamento das várias ciências que, de alguma forma, estudam a criminalidade têm-se caracterizado como uma atitude socialmente responsável e cientificamente necessária para as atividades de pesquisa que "pretendem ser qualquer outra coisa além de um acessório das forças de controle social sob a organização social vigente" (Taylor, et al., 1980, p. 56).

Assim, condizentes às esperanças que a sociedade deposita na atividade científica, apresenta-se aos pesquisadores da criminalidade a perspectiva promissora da Criminologia Critica, cujos princípios e métodos são claramente definidos por Taylor et al. (1980), como se segue:

1. A Criminologia Crítica considera que os processos envolvidos na criação e/ou violação das regras legais são de natureza totalmente social e predominantemente condicionadas pelos fatos da realidade material. Rompe com as explicações individuais (genéticos, psicológicos e similares) dos processos sociais e toma a economia política como determinante primário do modelo social. 
Vidas Presas: Uma Tentativa de Compreensão da Tragédia da Criminalidade...

2. Considera (e demonstra) que os processos envolvidos na criaçãodo-crime estão unidos com a base material do capitalismo contemporâneo e suas estruturas legais de dominação.

3. A base teórica da Criminologia Crítica é o materialismo histórico e seu método é a dialética.

4. O sentido prático da proposição teórica consiste em indicar, concretamente, no interesse de quem, contra quem e de que modo é exercido o controle social pelo sistema de justiça criminal nas sociedades de classe.

5. Sua produção (pesquisa, teorização e distribuição de conhecimento) está dirigida não às agências preocupadas com a conservação da atual organização social do poder, mas às instâncias envolvidas em lutar por mudanças. A lealdade do pesquisador para com a população consiste em que já tomou partido: seu trabalho será realimentado junto àqueles diretamente afetados pelas desigualdades pesquisadas.

6. A Criminologia Crítica não se limita a descrever ou prescrever; empenha-se em teoria e pesquisa como praxis: está preocupada em encorajar e participar das mudanças especificadas por seus preceitos e em desenvolver procedimentos de pesquisa relevantes para tal projeto.

7. A Criminologia Crítica se compromete normativamente com a abolição das desigualdades em riqueza e poder e com a tentativa de criar uma sociedade em que os fatos da diversidade humana não estejam sujeitos ao poder de criminalização.

Destacam-se aqui duas características da Criminologia Crítica consideradas especialmente promissoras. A primeira é que ela explicita seu projeto e revela sua utopia, diferenciando-se radicalmente das abordagens que ocultam ou ignoram seus objetivos sociais. A segunda é a própria proposta geral de trabalho, na qual a disposição de produzir conhecimento com e para a população que compõe o elenco oprimido da tragédia da criminalidade revela-se uma opção politicamente criativa, capaz de fortalecer a resistência aos processos de criminalização que vitimam a população pobre.

Por fim, registra-se a esperança de que essa proposta possa dar nova vitalidade à pesquisa dos fatores determinantes da violência social e interrom- 
per o verdadeiro processo de degradação que as agências da política criminal oficial impõem à produção científica na área. E a população aprisionada, por conhecer com intimidade o cotidiano da criminalidade e da violência carcerário-policial pode, por certo, contribuir muito para o trabalho de desvendar e enfrentar os fatores que produzem e reproduzem a tragédia criminal que vem se desenvolvendo inquietantemente na sociedade contemporânea.

\begin{abstract}
$*$
Rocha, L. C. (2006). Captured lives: an attempt of criminality tragedy comprehension together with prisoners characters. Psicologia USP, 17(3), 49-76.
\end{abstract}

Abstract: This article presents a research about the producer factors of criminality done in the beginning of 80s which, with the support of long interviews with female prisoners, elaborated a group of hypotheses to the understanding of the established relations that this phenomenon keeps with the poverty, with the police/prison violence and with the own specialized knowledge through which their acts and actors become object of knowledge. Its presentation, today, has two aims: the first is, in honor of recognition and gratitude to Sylvia Leser de Mello, to offer a simple example of one of many research adventures propitiated by her orientation. The second is to share with researchers the subject in study that, polemic and innovative to its epoch, keeps importance to its characteristic specially serious, nowadays, shown by approached issues.

Index terms: Criminality. Violence. Socioeconomic condition.

Rocha, L. C. (2006). Vies emprisonnées: une tentative de compréhension de la tragédie de la criminalité auprès de ses personnages prisionniers. Psicologia USP, 17(3), 49-76.

Résumé: Cet article présente une recherche sur les facteurs producteurs de la criminalité réalisée au début de la décennie 80 qui, en s'appuyant sur longs entretiens réalisées avec des prisonnières, a élaboré un 
ensemble d'hypothèses afin de comprendre les relations constitutives que ce phénomène maintient avec la pauvreté, avec la violence policière/ pénitentiaire et avec les propres savoirs par lesquels ses actes et ses auteurs deviennent objet de connaissance. Sa présentation, aujourd'hui, vise deux objectifs: le premier, en hommage et reconnaissance à Sylvia Leser de Mello, est celui d'offrir un simple exemple, parmi tant d'autres, d'une des nombreuses aventures de recherche rendue possible par son orientation. Le second est celui de partager avec des chercheurs qui s'intéressent au même thème une étude qui, polémique et innovatrice à l'époque de sa réalisation, conserve sa pertinence face, actuellement, aux caractéristiques particulièrement graves présentées par les questions abordées.

Mots-clés: Criminalité. Violence. Condition sócio-économique.

\section{Referências}

Benevides, M. V. (1983). Violência, povo e polícia. São Paulo: Brasiliense.

Bleger, J. (1980). Temas de psicologia. São Paulo: Martins Fontes.

Borda, O. F. (1983). Aspectos teóricos da pesquisa participante. In C. R. Brandão (Org.), Pesquisa participante (pp. 42-62). São Paulo: Brasiliense.

Brandão, C. R. (1984). Repensando a pesquisa participante. São Paulo: Brasiliense.

Castel, R. (1978). A ordem psiquiátrica: a idade de ouro do alienismo. Rio de Janeiro: Graal.

Feldman, M. P. (1979). O comportamento criminoso: uma análise psicológica. Rio de Janeiro: Zahar.

Foucault, M. (1972). Histoire de la folie à l'áge classique. Paris: Gallimard.

Mello, S. L. (1975). Psicologia e profissão em São Paulo. São Paulo: Ática.

Mello, S. L. (1988). Trabalho e sobrevivência: mulheres do campo e da periferia. São Paulo: Ática.

Ramalho, J. R. (1979). O mundo do crime: a ordem pelo avesso. Rio de Janeiro: Graal.

Rocha, L. C. (1984). Vidas presas: uma tentativa de compreender a tragédia da criminalidade junto às suas personagens oprimidas. Dissertação de Mestrado, Instituto de Psicologia, Universidade de São Paulo, São Paulo.

Rocha, L. C. (1994). A prisão dos pobres. Tese de Doutorado, Instituto de Psicologia, Universidade de São Paulo, São Paulo. 


\section{Luiz Carlos da Rocha}

Senderey, I. D. (1978). Manual de criminologia. São Paulo: José Bushatsky.

Sutherland, E. H. (1949). Princípios de criminologia. São Paulo: Martins Fontes.

Taylor, I., Walton, P., \& Young, J. (1980). Criminologia crítica. Rio de Janeiro: Graal.

Violante, M. L. V. (1984). O dilema do decente malandro. São Paulo: Cortez.

Recebido em: 14/11/2006

Aceito em: 27/11/2006 